\title{
1 Using genomic prediction to detect microevolutionary change of a quantitative \\ 2 trait
}

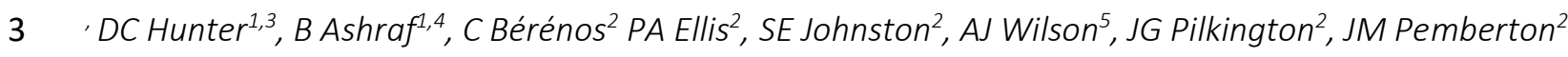

4 \& J Slate 1

5

6
1. Department of Animal \& Plant Sciences, University of Sheffield, Sheffield S10 2TN, UK

2. Institute of Evolutionary Biology, University of Edinburgh, Edinburgh EH9 3FL, UK

3. School of Biology, University of St Andrews, St Andrews KY16 9ST, UK

4. Department of Anthropology, Durham University, Durham, DH1 3LE, UK

5. Centre of Ecology and Conservation, College of Life and Environmental Sciences, University of Exeter, Penryn, TR10 9FE, UK

\section{Abstract}

Detecting microevolutionary responses to natural selection by observing temporal changes in individual breeding values is challenging. The collection of suitable datasets can take many years and disentangling the contributions of the environment and genetics to phenotypic change is not trivial. Furthermore, pedigree-based methods of obtaining individual breeding values have known biases. Here, we apply a genomic prediction approach to estimate breeding values of adult weight in a 35-year dataset of Soay sheep (Ovis aries). During the study period adult body weight decreased, but the underlying genetic component of body weight increased, at a rate that is unlikely to be attributable to genetic drift. Thus cryptic microevolution of greater adult body weight has probably occurred. Using genomic prediction to study microevolution in wild populations can remove the requirement for pedigree data, potentially opening up new study systems for similar research.

\section{Keywords}

Microevolution, genomic prediction, cryptic evolution, genomic estimated breeding value, Soay sheep 
bioRxiv preprint doi: https://doi.org/10.1101/2021.01.06.425564; this version posted January 8,2021 . The copyright holder for this preprint (which was not certified by peer review) is the author/funder, who has granted bioRxiv a license to display the preprint in perpetuity. It is made available under aCC-BY-NC-ND 4.0 International license.

Genomic prediction and microevolution in Soay sheep

\section{Introduction}

When directional selection on a single trait is carried out in an experimental evolution study, or in animal and plant breeding, the response to selection is predictable. The Breeder's Equation [1], $R=h^{2} S$, predicts the response $(R)$ as the product of the strength of selection $(S)$ and the narrow-sense heritability $\left(h^{2}\right)$ and it usually gives a reasonably accurate estimate of the actual observed response [2]. However, in more complex systems, such as in wild populations, the response is much harder to predict $[3,4]$. The reasons why a trait may not evolve as expected include: (i) unmeasured genetic correlations between the trait and other fitness-related traits $[3,5]$; fluctuating environmental conditions causing variation in either (ii) the heritability of the trait [6] or (iii) the strength of selection [7], or both [8]; and (iv) cryptic microevolution [9], where the trait actually has responded to selection, but a change in environmental conditions has caused the phenotypic trend to mask the underlying genetic trend. More generally, the term 'evolutionary stasis' has been used to describe the absence of an expected response to selection [4]. The upshot is that identifying microevolutionary responses to natural selection is nontrivial.

One way to detect microevolution in a population is to estimate each individual's 'genetic merit' or breeding value, and test whether population-wide breeding values have changed temporally, in line with predictions from measured selection differentials. If phenotypic and multigenerational pedigree data are available than estimated breeding values (EBVs) can be obtained using restricted maximum likelihood (REML) procedures in linear mixed models - 'animal models' [10, 11]. Exploring temporal trends in EBVs rapidly gained popularity once animal models began to be applied to studies of natural populations $[9,12,13]$. Unfortunately, it was not long before problems and biases with the approach were identified $[14,15]$. First, pedigrees in natural populations are usually small and unbalanced, relative to those used in applied breeding. Therefore, many individuals lack 'connectedness' - they have relatively few phenotyped relatives in the dataset. EBVs of these individuals are heavily dependent on the individual's phenotype, and so environmental influences on the phenotype can be confounded with genetic effects, causing error and bias in the EBV [15]. In studies looking at microevolutionary trends, this can cause spurious evidence for microevolutionary change, especially when 'unconnected' individuals are clustered at the beginning or end of the time series and have experienced similar environments. A second major problem is that EBVs from animal models are typically treated as point estimates, with any uncertainty or error in their estimate being ignored. Ignoring this uncertainty causes temporal trends in EBVs to be anti-conservative, i.e. prone to false positive inferences, especially as errors tend to be correlated among relatives [16]. 
bioRxiv preprint doi: https://doi.org/10.1101/2021.01.06.425564; this version posted January 8,2021 . The copyright holder for this preprint

(which was not certified by peer review) is the author/funder, who has granted bioRxiv a license to display the preprint in perpetuity. It is made available under aCC-BY-NC-ND 4.0 International license.

Genomic prediction and microevolution in Soay sheep

61 To overcome the problems described above, several best practice steps have been proposed. First, 62 fitting terms such as year of birth or measurement in an animal model ('de-trending') should reduce 63 the risk of temporal environmental heterogeneity causing spurious trends in EBVs, although it may not eliminate it completely [15]. Second, taking a Bayesian approach to estimate breeding values allows the uncertainty in estimates to be accommodated into the analysis of temporal trends [16]. Bayesian animal models return a posterior distribution of EBVs, rather than a point estimate, and by regressing every posterior sample of cohort mean EBVs on year, the slope can be estimated with an appropriate, confidence interval [16]. In their paper demonstrating this approach Hadfield and colleagues [16] pointed out that there are two different questions that can be asked with the posterior distributions of EBVs. Is the microevolutionary trend statistically significant? And is the trend of greater magnitude than can be expected due to genetic drift? The second question is the biologically more relevant, in the context of a genetic response to selection, and can be tested with 'gene-dropping' simulations. By randomly sampling from the posterior distribution of the trait's additive genetic variance, founders in the pedigree can be assigned a simulated breeding value. Simulated breeding values are then transmitted down the pedigree, by assigning offspring a midparental EBV. The gene-dropped EBVs can be regressed against time to estimate the microevolutionary trend. If the process is repeated for each posterior estimate of the additive genetic variance, then a null distribution of temporal trends under a scenario of no selection (and thus no response) is generated; i.e. the expectation due to genetic drift.

In their paper highlighting how microevolutionary trends derived from point estimates of breeding values tended to be anticonservative, Hadfield and colleagues [16] illustrated the problem with two empirical datasets. One of these was an example of apparent cryptic microevolution of adult body size in a free-living population of feral Soay sheep [17]. In the study population, adult weight is positively associated with increased winter survival and is heritable [18-20], and therefore should be increasing in response to directional selection. In fact, during the period studied by Wilson and colleagues (19852005), adult body weight declined over time by around 100-200g per year [21]. In contrast, during the same period, animal model-derived EBVs for adult weight increased by around 5-10g per year. In other words, microevolution was proceeding as expected, but was masked by non-genetic effects causing body sizes to be smaller [19]. Birth year and capture year were fitted in the animal models, thus detrending the data for possible environmental effects on different cohorts, prior to estimating the temporal trends. Furthermore, the phenotypic and genetic trends were in opposite directions, which is generally considered to be a sign that apparent microevolution is not being driven by an unappreciated contribution of an environmental effect on phenotype [15]. However, the original analysis was anticonservative as inference on the genetic trend failed to properly account for uncertainty in EBV estimation. Re-analysis by Hadfield et al. using a Bayesian method to incorporate the posterior 
bioRxiv preprint doi: https://doi.org/10.1101/2021.01.06.425564; this version posted January 8,2021 . The copyright holder for this preprint (which was not certified by peer review) is the author/funder, who has granted bioRxiv a license to display the preprint in perpetuity. It is made available under aCC-BY-NC-ND 4.0 International license.

Genomic prediction and microevolution in Soay sheep

95

96

97

98

99

100

101

102

103

104

105

106

107

108

109

110

111

112

113

114

115

116

117

118

119

120

121

122

123

124

125

126

distributions of EBVs, yielded an estimate of the temporal increase in breeding values that was quantitatively unchanged, but no longer statistically significant. Thus, the more conservative (and correct) analytical approach [16] no longer supported an evolutionary response to selection on larger adult body size.

In this paper, we revisit the question of whether adult weight in Soay sheep is responding to natural selection, but with several potential improvements over previous investigations. First, we use a larger dataset that extends the time series studied by Wilson by a further 10 years. Second, and perhaps most obviously different to previous work, we use genomic prediction rather than a pedigree to estimate breeding values. Genomic prediction [22], is a tool widely used in animal and plant breeding to estimate quantitative genetic parameters from marker data. It works by exploiting the fact that when marker density is sufficiently high, some typed SNP markers are in linkage disequilibrium (LD) with unknown causal loci, and the contribution of each SNP (and the unknown loci it tags) to phenotypic variation can be estimated. By estimating SNP effects in one part of the dataset (the training population) and using those estimates to predict breeding values in a second dataset of genotyped but not phenotyped individuals (the test population) it is possible to obtain genomic estimated breeding values (GEBVs) that are independent of the focal individual's phenotype. Furthermore GEBVs are less influenced by the number of phenotyped close relatives a focal individual has in the dataset, compared to animal modelderived EBVs [23]. Genomic prediction models can include known fixed and random effects such as sex, age, year of birth and year of measurement. Thus many of the known biases and problems caused by animal models being run in relatively small and unbalanced pedigrees [15] are overcome. We use a Bayesian method to estimate the GEBVs, so posterior distributions of GEBVs can be used to account for uncertainty in their estimates, in the same way that Hadfield recommends for EBVs derived from Bayesian animal models of pedigree data. Third, we use gene-dropping in the pedigree, to formally test whether any temporal patterns are likely to be due to a response to selection or are explainable by genetic drift. However, because the genomic prediction method estimates the contribution of each SNP to variation in weight, the genetic drift simulations are explicitly based on a description of the trait's genetic architecture (the number and effect size of causal loci) rather than assuming an infinitesimal model.

Our intention is that, in addition to revisiting a well-known, but still unresolved, case study of possible cryptic microevolution, this paper will illustrate a genomic prediction-based framework to study microevolutionary change that can be readily adopted by other researchers working on evolution and adaptation in natural populations. 
bioRxiv preprint doi: https://doi.org/10.1101/2021 01.06.425564; this version posted January 8, 2021. The copyright holder for this preprint (which was not certified by peer review) is the author/funder, who has granted bioRxiv a license to display the preprint in perpetuity. It is made available under aCC-BY-NC-ND 4.0 International license.

Genomic prediction and microevolution in Soay sheep

\section{Methods}

The study population

The Soay sheep is a primitive feral breed inhabiting the St Kilda archipelago, off the NW of Scotland. Since 1985 , the population in the Village Bay area of the largest island, Hirta $\left(57^{\circ} 48^{\prime} \mathrm{N}, 8^{\circ} 37^{\prime} \mathrm{W}\right)$, has been the subject of a long-term individual based study [24]. Most of the sheep resident in the study area are ear-tagged and weighed shortly after birth and followed throughout their lifetime. Ear punches and blood samples suitable for DNA analysis are collected at tagging. During the annual 'catch' in August, sheep are captured and morphological measurements are taken. Winter mortality is monitored, with the peak of mortality occurring at the end of winter/early spring, and ca. $80 \%$ of all deceased sheep are found. To date, extensive life history data have been collected for over 10,000 sheep. More details of the study can be found elsewhere [24].

\section{Phenotypes}

Weight measurements were taken on live animals, as described elsewhere [20, 25]. Weight data were restricted to animals captured in August, that were at least 28 months old, to remove most complications of growth $[20,25]$. The inclusion of measurements taken outside of August would not have resulted in a much larger sample size, but would have complicated analyses as animals lose weight at different rates later in the year. Note that Wilson et al. (2007) included 0 month, 4 month and 16 month old animals in their analyses [17] but weight has lower additive genetic variance and heritability at these ages. Given that we were using repeated measurements taken across an individual's lifetime, rather than running age-specific models, it was deemed prudent to restrict the analyses to older animals.

\section{Genotyping}

Genotyping of the population was performed using the Illumina Ovine SNP50 beadchip array, developed by the International Sheep Genomics Consortium (ISGC) [26] Genotyping was performed at the Wellcome Trust Clinical Research Facility Genetics Core (Edinburgh, UK). Details about the genotype calling and quality control of the data are available elsewhere [20, 27]. Briefly, pruning of SNPs and individuals was performed using Plink v 1.9 [28]. Only autosomal SNPs were analysed, as BayesR cannot distinguish between autosomal and sex-linked loci (the sheep X chromosome represents $\sim 5 \%$ of the total genome). SNPs were removed if they had more than 0.02 missing data, a minor allele frequency less than 0.01 or a Hardy-Weinberg Equilibrium Test p value $<0.00001$. Individuals were retained if they were typed for at least 0.95 of SNPs. After pruning, there were 35,882 SNPs in the dataset. 1168 individuals were genotyped and phenotyped, and there were an additional 5627 animals which were 
bioRxiv preprint doi: https://doi.org/10.1101/2021.01.06.425564; this version posted January 8,2021 . The copyright holder for this preprint (which was not certified by peer review) is the author/funder, who has granted bioRxiv a license to display the preprint in perpetuity. It is made available under aCC-BY-NC-ND 4.0 International license.

Genomic prediction and microevolution in Soay sheep

159

160

161

162

163

164

165

166

167

168

169

170

171

172

173

174

175

176

177

178

179

180

181

182

183

184

185

186

187

188

189

genotyped but not phenotyped (because they died or emigrated from the study area before the age of 28 months), whose weight GEBVs could nonetheless be estimated as a test population (see below).

\section{Genomic prediction of weight GEBVs}

Soay sheep adult weight is a polygenic trait with a moderate heritability and no individual loci were significant in previous GWAS [20, 25, 29]. Genomic prediction of GEBVs was performed using the BayesR method [30] implemented in the BayesR v0.75 software package [31]. We have previously shown that BayesR-derived GEBVs of Soay sheep morphological traits, including adult weight, have a high accuracy ( 0.64) [29]. BayesR models SNP effects as a number of distributions of different effect sizes, including one of zero effect. We assumed there were 4 distributions of effect size of $0,0.0001$, 0.001 and 0.01 of the phenotypic variance. Dirichlet priors for the number of pseudo-observations (SNPs) in each distribution were set to 1, 1, 1 and 5. Priors for the genetic and residual variances were chosen as a scaled inverse-chi squared distribution with scaling parameters of 1.2 and 2.5 and degrees of freedom set to 10 . The MCMC chain was run for a total of 120,000 iterations with a burnin of 20,000 and a thinning interval of 10 , meaning there were 1000 posterior samples of the GEBVs for each individual.

In the BayesR models all phenotyped and genotyped animals $(n=1168)$ were treated as a training population and all animals for whom we had genotypes but no phenotypes ( $n=5627)$ were the test population. The phenotypes used in the BayesR analysis were obtained by first fitting a linear mixed model (see [29]) that included individual identity (to account for repeated measures), birth year and capture year as random effects and sex and age as fixed effects. The random effect of individual identity was used as the phenotype.

\section{Measuring microevolutionary change}

To test for microevolutionary change we explored whether GEBVs for weight changed as a function of birth year. The cohort mean GEBVs were regressed against birth year, weighting each year by the sample size. We used all 1000 posterior samples from the BayesR chain and determined a 95\% confidence interval for the slope of cohort mean GEBV on year; i.e. the approach advocated by Hadfield [16] and subsequently adopted elsewhere [32-34]. The probability of stasis or a decline in GEBVs was determined as the proportion of the 1000 models where the slope was $\leq 0$. We also explored an alternative approach of using individual GEBVs and fitting linear mixed models with birth year included as both a fixed effect and as a random effect. The birth year random term was fitted to account for between-year heterogeneity of variances in GEBVs. In fact, the birth year random effect explained less 
bioRxiv preprint doi: https://doi.org/10.1101/2021.01.06.425564; this version posted January 8,2021 . The copyright holder for this preprint (which was not certified by peer review) is the author/funder, who has granted bioRxiv a license to display the preprint in perpetuity. It is made available under aCC-BY-NC-ND 4.0 International license.

Genomic prediction and microevolution in Soay sheep

190

191

192

193

194

195

196

197

198

199

200

201

202

203

204

205

206

207

208

209

210

211

212

213

214

215

216

217

218

219

220

221

222

than $1 \%$ of the variance in GEBVs and the mixed model approach yielded almost identical results to the regressions of cohort mean GEBVs on year (electronic supplementary material).

The main results section reports findings from both the training and test populations combined, in all cohorts from 1990 onwards. We omitted earlier years because they had less than 100 individuals (Table S1) and earlier cohorts were treated slightly different in the gene-dropping simulations of drift (see below). In the electronic supplementary material we show results from 1980 onwards and also from 2005 onwards, i.e. in the cohorts born since Wilson's study [17]. Similarly, we compare results from models that contained training and test population individuals with those that just contained the test population. The main findings are not sensitive to the choice of cohorts or populations used.

\section{Simulating microevolutionary change under genetic drift}

Simulations to explore microevolutionary changes expected under genetic drift used a gene-dropping approach, similar in concept to those introduced by Hadfield [16] and adopted by others [34]. However, whereas previous methods have dropped breeding values down a pedigree, we dropped individual SNPs down the pedigree and then calculated GEBVs from the estimated effect sizes of SNPs. This has the advantage that instead of assuming the trait is a near-infinitesimal polygenic trait, the GEBVs are predicted using empirical estimates of the number and effect size of causal loci, as well as realistic recombination fractions between them. Gene-dropping was performed using the SimPed program [35]. SimPed can handle SNP genotypes or haplotype blocks of linked SNPS. To ensure that realistic levels of linkage disequilibrium between linked SNPs was present in the simulated datasets, we used haplotypes, after first phasing the real data. Phasing was performed and missing genotypes were imputed using Beagle v5.0 [21], assuming an effective population size of 200. Phased haplotypes were then randomly assigned to founder individuals in the Soay sheep pedigree. Individuals born before 1990 were treated as founders. The SimPed gene-dropping simulations use known linkage distances between all of the SNPs to ensure that realistic amounts of recombination occur during each meiosis. We used previous estimates of recombination fractions in the Soay sheep pedigree [27]. Because SimPed can only run one chromosome of markers at a time, we concatenated all of the SNPs from different chromosomes to create one 'super chromosome', but assumed a recombination fraction of 0.5 between the last SNP on one chromosome and the first SNP on the next chromosome. This effectively ensures independent segregation of unlinked chromosomes. In cases where an individual was missing parental data, a haplotype was randomly assigned from an individual of the correct sex that was born between 2 and 10 years prior. Handling missing data in this way ensures that complete genotypes were simulated for all individuals, while accounting for any temporal changes in allele frequencies in the population. Alleles 
bioRxiv preprint doi: https://doi.org/10.1101/2021.01.06.425564; this version posted January 8, 2021. The copyright holder for this preprint

(which was not certified by peer review) is the author/funder, who has granted bioRxiv a license to display the preprint in perpetuity. It is made available under aCC-BY-NC-ND 4.0 International license.

Genomic prediction and microevolution in Soay sheep

223 are passed from parents to offspring following Mendelian rules of independent assortment and

224 recombination. Each SimPed run generates genotypes at every SNP in every individual in the pedigree.

225 Multilocus genotypes were converted to GEBVs by summing the allelic effects at each locus, using the

226 posterior estimated SNP effects from the BayesR runs of the real dataset. 1000 simulations were run,

227 each one using an estimate of SNP effect sizes from a different posterior sample of the BayesR MCMC

228 chain used to perform the genomic prediction. i.e. The first gene-dropped data set used estimated SNP

229 effects from the $1^{\text {st }}$ posterior sample of the MCMC chain, the second gene-dropped data set used

230 estimated SNP effects from the $2^{\text {nd }}$ posterior sample, and so on. This ensures that uncertainty in the

231 posterior estimate of each SNP effect size is carried into the gene-dropping simulations.

232 At the end of the gene-dropping process there were 1000 simulated datasets that could be compared

233 to the 1000 MCMC samples of the real dataset. Thus, it was possible to determine whether observed

234 changes in GEBVs over time were likely to be greater than can be expected from genetic drift alone.

235 For each gene-dropped dataset we regressed the cohort mean GEBV on birth year weighting each year

236 by sample size, exactly like in the real dataset. For each of the 1000 comparisons the slope of birth year

237 from the gene-dropped dataset was subtracted from the slope of birth year in the real dataset, in order

238 to generate a posterior distribution of temporal changes in GEBVs relative to those expected under

239 drift. The probability of the observed microevolutionary change exceeding that expected from genetic

240 drift was estimated as the proportion of the 1000 comparisons where the gene-dropped slope was

241 greater than the real data slope.

242

243 Genomic prediction using a 'leave one cohort out' approach.

244 An additional genomic prediction analysis was run in which each cohort was treated as a test population

245 (i.e. phenotypes unknown) and all of the other cohorts were treated as a training population. Thus, for 246 every individual in the test cohort, the genomic prediction did not utilise the phenotypes of that 247 individual or any other individual born in the same year. This ensures not only that the focal individual's 248 phenotype does not contribute to its GEBV, but also reduces the risk that estimated SNP effect sizes 249 are influenced by between-cohort level covariances between allele frequencies and adult weight. The results support the main findings and are included in the electronic supplementary material. 
bioRxiv preprint doi: https://doi.org/10.1101/2021 01 06.425564; this version posted January 8, 2021. The copyright holder for this preprint (which was not certified by peer review) is the author/funder, who has granted bioRxiv a license to display the preprint in perpetuity. It is made available under aCC-BY-NC-ND 4.0 International license.

Genomic prediction and microevolution in Soay sheep

251

252

253

254

255

256

257

258

259

260

261

262

263

264

265

266

267

268

269

270

271

272

273

274

275

276

277

278

279

280

281

282

\section{Results}

Temporal changes in adult body weight

Adult body weight declined over the course of the study period (Figure 1a), by an average of $0.066 \mathrm{~kg}$ per year $(P=0.004)$. However, in the period 2005-2015, i.e. in the cohorts born since the Wilson et al. (2007) study [17], there has been a non-significant increase of 0.174 per year $(P=0.15$; See electronic supplementary material).

\section{Microevolutionary changes in body weight GEBVs}

Between 1990 and 2015 mean cohort adult body weight GEBVs increased by approximately 0.011 (95\% credible interval 0.001-0020) kg per year (Fig 1b). The posterior probability of no genetic change was low (probability $=0.014$ ), using the conservative approach of regressing the posterior distribution of cohort mean GEBVs on year. When comparing the posterior distribution of real cohort mean GEBVs regressed on year to those generated under gene-dropping genetic drift simulations (Fig 1c), the distribution of the difference between real and gene-dropped regression coefficients was consistent with the observed trends being larger than expected from genetic drift; probability that the slope is explainable by drift alone $=0.057$. Thus, while genetic drift cannot be ruled out as an explanation for the observed increase in adult weight GEBVs, a response to selection for greater weights is perhaps more likely. In the electronic supplementary material we show that the main conclusions would be the same if all individuals from the 1980 cohort onwards are included, or if the analysis is restricted to only test population individuals from either 1980 or 1990 onwards.

\section{Discussion}

The primary aim of this study was to investigate the use of genomic prediction as an alternative to a pedigree-based animal model approach to studying microevolutionary trends. There are two main advantages to a genomic prediction approach. First, it avoids the necessity of reconstructing a pedigree, which potentially opens the way to microevolutionary studies being conducted in a greater number of systems, including those with very large population sizes, long generation times or high rates of dispersal. Second, most of the potential biases associated with pedigree-based approaches to studying microevolution can be avoided. For example, when a focal individual is part of a test population, its phenotype is not used to predict its GEBV, avoiding the problem that phenotyped individuals with low pedigree connectedness will tend to have GEBVs that reflect the environmental contribution to their phenotype [15]. Furthermore, simulations and empirical data have shown that the accuracy of an individual's genomic estimated breeding value is much less sensitive to the number of relatives than 
bioRxiv preprint doi: https://doi.org/10.1101/2021.01.06.425564; this version posted January 8,2021 . The copyright holder for this preprint (which was not certified by peer review) is the author/funder, who has granted bioRxiv a license to display the preprint in perpetuity. It is made available under aCC-BY-NC-ND 4.0 International license.

Genomic prediction and microevolution in Soay sheep

283

284

285

286

287

288

289

290

291

292

293

294

295

296

297

298

299

300

301

302

303

304

305

306

307

308

309

310

311

312

313

when pedigree-based animal models are used [23]. Genomic approaches often outperform pedigreebased ones, but especially when close relatives are absent from the dataset [23]. There are further improvements that could be made to the approach used here. Most notably, there is not yet an easyto-implement single-step framework that for allows for genomic prediction models to be run when there are repeated measures and other random effects that might be fitted. Here, we used a two-step approach, running a mixed model to estimate phenotypes adjusted for non-genetic effects, before running the genomic prediction models. This does mean that uncertainty in the adjusted phenotypes are not carried through to the downstream analysis, although uncertainty in the underlying breeding values is accounted for.

We extended a time series examining whether there was a microevolutionary response to selection for larger body weight in Soay sheep. Previous work had suggested breeding values for adult weight had increased [17], but subsequent scrutiny suggested the temporal change may be indistinguishable from stasis [16]. Here, the addition of 10 more years of data confirmed that breeding values have increased by approximately $0.01 \mathrm{Kg}$ per year. The standard deviation of adult weight, after correcting for sex and age, is $\sim 7.4 \mathrm{~kg}$ and the mean generation time is $\sim 4$ years. Therefore, the observed rate of microevolutionary change is $\sim 0.01 / 7.4 * 4=0.0054$ Haldanes. The largest published compilation of rates of microevolutionary change [36], contains over 2000 estimates from vertebrate populations, albeit mostly estimated from phenotypic rather than genetic changes. Over half of those estimates exceed 0.0054 Haldanes. Clearly there will be relatively wide confidence intervals on our (and any other) estimate of rates of microevolution, but it seems that the rate observed here is unremarkable. Thus, there is cause for optimism that genomic prediction approaches to studying microevolutionary change will not be limited to cases of very large responses to selection.

Although, the earlier evidence for breeding values increasing was equivocal $[16,17]$, adult weight at the phenotypic level was decreasing. However, this phenotypic decline seems to have been arrested and possibly reversed in the years since the earlier study. It should be noted that temporal trends in adult weight and in GEBVs between 2005-2015 are not significant, because the sample size is considerably smaller than that of the entire data set. However, the regression slopes of cohort mean GEBVs on year are almost identical to those of the longer time series starting in 1980 or 1990 . Thus, while the phenotypic trends for adult weight have likely changed since the Wilson et al. (2007) study, the genetic trends appear to have been more constant.

This is not the first study to have used gene-dropping simulations to test whether observed microevolutionary trends are greater than expected by genetic drift [32-34, 37]. However, other studies have used estimates of additive genetic variance from animal models to assign founder individuals a 
Genomic prediction and microevolution in Soay sheep

316 breeding value, with offspring inheriting midparental values. It is assumed that the phenotype has a

317 classical polygenic genetic architecture. Adult weight in Soay sheep is in fact a largely polygenic trait

$318[20,25]$, but nonetheless the gene-dropping simulations explicitly modelled the number, effect size and

319 genomic location of causal loci, using estimated SNP effects from each posterior sample of the genomic

320 prediction analysis. Gene-dropping individual loci allows for variable effect sizes, and accommodates

321 features that cannot be modelled by gene-dropping breeding values, such as the amount of linkage,

322 recombination and linkage disequilibrium between causal loci. Thus, gene-dropping simulations that

323 explicitly model a trait's architecture should give a better reflection of what changes can occur due to

324 drift, thereby making inferences about whether trends are due to selection more robust.

325 In summary, we have introduced a genomic approach to studying microevolutionary trends that should

326 be robust and applicable to other systems. In the case of Soay sheep, there is convincing evidence that

327 breeding values for adult weight have been increasing by around $0.01 \mathrm{Kg}$ per year over a >30 year

328 period, and that the trend has likely been driven by a response to selection for larger size rather than

329 genetic drift. The rate of increase in breeding values has remained constant both during and after a period when phenotypic values were declining due to environmental or demographic effects. 
Genomic prediction and microevolution in Soay sheep

332 Data Accessibility. Data and scripts required to run the analyses can be found on Dryad:

334 Authors' Contributions. D.C.H., B.A and J.S performed the analyses. S.E.J, P.A.E, and C.B. prepared the 335 DNA samples and generated and cleaned the SNP data. J.G.P and J.M.P collected field data and 336 coordinated field expeditions. J.S, D.C.H, B.A., A.J.W and J.M.P conceived the research idea. J.S. wrote 337 the first draft of the manuscript with contributions from all authors.

338 Funding. This work was funded by a Natural Environment Research Council (NERC) grant, 339 (NE/M002896/1) awarded to JS and JMP. SNP genotyping was mostly funded by a European Research 340 Council (ERC) grant (Wild Evolutionary Genomics) awarded to JMP.

341 Acknowledgements. The National Trust for Scotland (NTS) granted permission to carry out field work 342 on St Kilda. QinetiQ and Eurest provided fieldwork logistical support. We are grateful to the many 343 volunteers who have helped with field data collection on St Kilda over the last three decades. 344 Genotyping was carried out at the Wellcome Trust Clinical Research Facility Genetics Core. 
Genomic prediction and microevolution in Soay sheep

\section{$346 \quad$ Figure Legends}

347 Figure 1: (A) Adult weight (corrected for age and sex) has declined over the course of the long term

348 study. (B) GEBVs for adult birth weight have increased over the course of the study. Bold blue line is 349 posterior cohort means. Light blue shading shows the 95\% posterior credible interval. Thin grey lines

350 are the 1000 gene-dropped simulations, showing the expected changes in adult weight GEBVs due to

351 genetic drift. (C) The distribution of the difference in slope of GEBV against year for the real data minus

352 the gene-dropped data. The proportion of slope differences $<0$ gives the probability that the observed

353 slope is caused by genetic drift. 
bioRxiv preprint doi: https://doi.org/10.1101/2021.01.06.425564; this version posted January 8, 2021. The copyright holder for this preprint (which was not certified by peer review) is the author/funder, who has granted bioRxiv a license to display the preprint in perpetuity. It is made available under aCC-BY-NC-ND 4.0 International license.

Genomic prediction and microevolution in Soay sheep
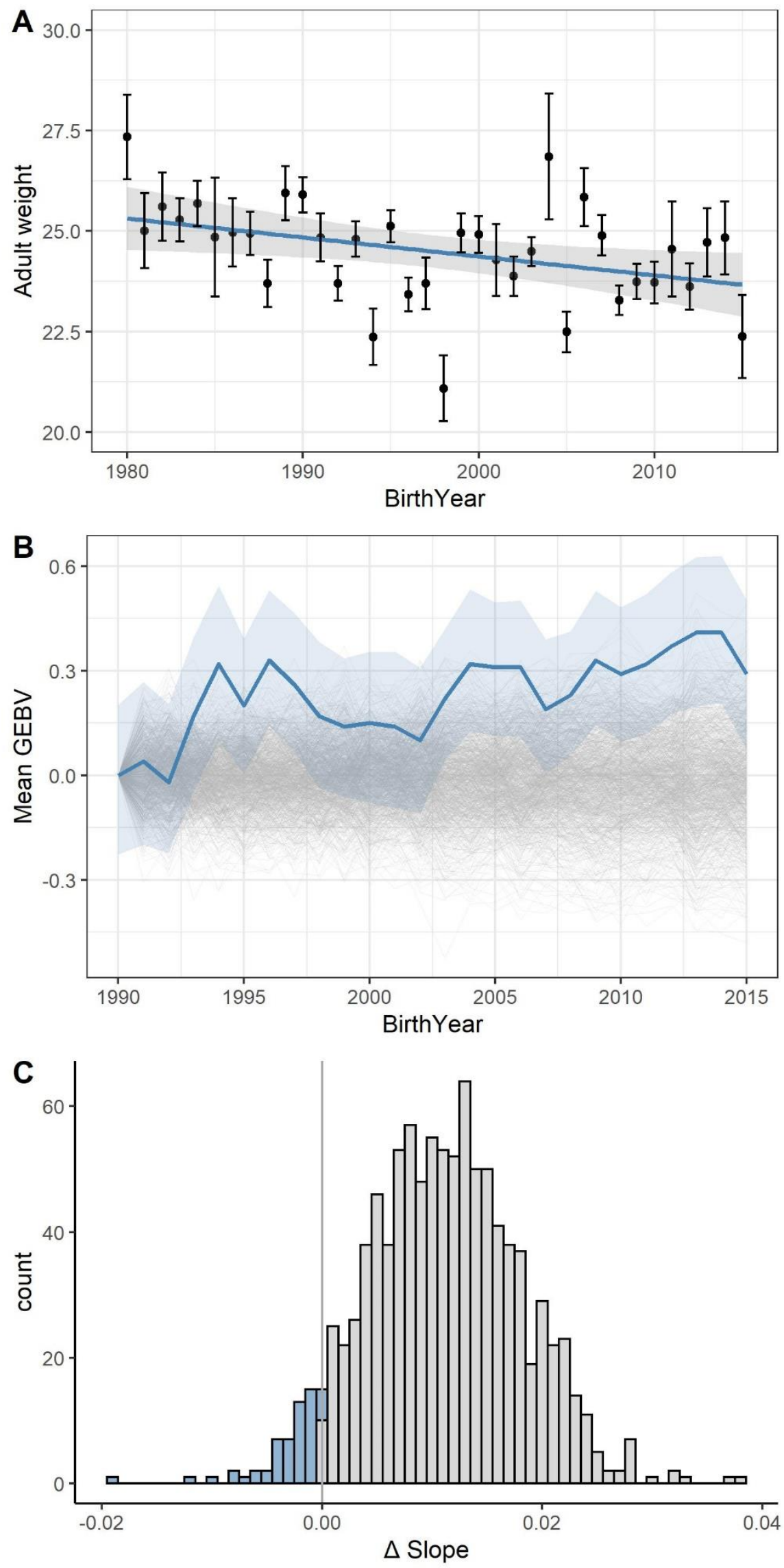
bioRxiv preprint doi: https://doi.org/10.1101/2021.01.06.425564; this version posted January 8,2021 . The copyright holder for this preprint (which was not certified by peer review) is the author/funder, who has granted bioRxiv a license to display the preprint in perpetuity. It is made available under aCC-BY-NC-ND 4.0 International license.

Genomic prediction and microevolution in Soay sheep

References
358

359 [1] Lush, J.L. 1943 Animal breeding plans. 2 ed, lowa State College Press; 437 p.

360 [2] Falconer, D. 1989 Introduction to Quantitative Genetics. Third ed. New York, Longman.

361 [3] Morrissey, M.B., Kruuk, L.E. \& Wilson, A.J. 2010 The danger of applying the breeder's equation in

362

363

364

365

366

367

368

369

370

371

372

373

374

375

376

377

378

379

380

381

382

383

384

385

386

387

388

389

390

391

392

393

394

395

396

397

398

399

400

401

402

403

404

observational studies of natural populations. J Evol Biol 23, 2277-2288. (doi:10.1111/j.1420-

9101.2010.02084.x).

[4] Merilä, J., Sheldon, B.C. \& Kruuk, L.E.B. 2001 Explaining stasis: microevolutionary studies in natural populations. Genetica 112, 199-222. (doi:10.1023/A:1013391806317).

[5] Lande, R. \& Arnold, S.J. 1983 The Measurement of Selection on Correlated Characters. Evolution 37, 1210-1226. (doi:10.1111/j.1558-5646.1983.tb00236.x).

[6] Hoffmann, A.A. \& Merila, J. 1999 Heritable variation and evolution under favourable and unfavourable conditions. Trends Ecol Evol 14, 96-101. (doi:10.1016/s0169-5347(99)01595-5).

[7] Grant, B.R. \& Grant, P.R. 1993 Evolution of Darwin Finches Caused by a Rare Climatic Event. Proc. R. Soc. B. 251, 111-117. (doi:10.1098/rspb.1993.0016).

[8] Wilson, A.J., Pemberton, J.M., Pilkington, J.G., Coltman, D.W., Mifsud, D.V., Clutton-Brock, T.H. \& Kruuk, L.E.B. 2006 Environmental coupling of selection and heritability limits evolution. PLoS Biology 4, 1270-1275. (doi:10.1371/journal.pbio.0040216).

[9] Merilä, J., Kruuk, L.E.B. \& Sheldon, B.C. 2001 Cryptic evolution in a wild bird population. Nature 412, 76-79. (doi:10.1038/35083580).

[10] Kruuk, L.E.B. 2004 Estimating genetic parameters in natural populations using the 'animal model'. Philosophical Transactions of the Royal Society of London, Series B 359, 873-890.

(doi:10.1098/rstb.2003.1437).

[11] Kruuk, L.E.B., Slate, J. \& Wilson, A.J. 2008 New Answers for Old Questions: The Evolutionary Quantitative Genetics of Wild Animal Populations. Annual Review of Ecology Evolution and Systematics 39, 525-548. (doi:10.1146/annurev.ecolsys.39.110707.173542).

[12] Coltman, D.W., O'Donoghue, P., Jorgenson, J.T., Hogg, J.T., Strobeck, C. \& Festa-Bianchet, M. 2003 Undesirable evolutionary consequences of trophy hunting. Nature 426, 655-658.

(doi:10.1038/nature02177).

[13] Garant, D., Kruuk, L.E.B., McCleery, R.H. \& Sheldon, B.C. 2004 Evolution in a changing environment: A case study with great tit fledging mass. Am. Nat. 164, E115-E129. (doi:10.1086/424764).

[14] Hadfield, J.D. 2010 MCMC Methods for Multi-Response Generalized Linear Mixed Models: The MCMCgImm R Package. Journal of Statistical Software 33, 1-22. (doi:10.18637/jss.v033.i02).

[15] Postma, E. 2006 Implications of the difference between true and predicted breeding values for the study of natural selection and micro-evolution. Journal Of Evolutionary Biology 19, 309-320. (doi:10.1111/j.1420-9101.2005.01007.x).

[16] Hadfield, J.D., Wilson, A.J., Garant, D., Sheldon, B.C. \& Kruuk, L.E.B. 2010 The Misuse of BLUP in Ecology and Evolution. Am. Nat. 175, 116-125. (doi:10.1086/648604).

[17] Wilson, A.J., Pemberton, J.M., Pilkington, J.G., Clutton-Brock, T.H., Coltman, D.W. \& Kruuk, L.E.B. 2007 Quantitative genetics of growth and cryptic evolution of body size in an island population. Evol. Ecol. 21, 337-356. (doi:10.1007/s10682-006-9106-z).

[18] Milner, J.M., Albon, S.D., Illius, A.W., Pemberton, J.M. \& Clutton-Brock, T.H. 1999 Repeated selection of morphometric traits in the Soay sheep on St Kilda. Journal Of Animal Ecology 68, 472488. (doi:10.1046/j.1365-2656.1999.00299.x).

[19] Ozgul, A., Tuljapurkar, S., Benton, T.G., Pemberton, J.M., Clutton-Brock, T.H. \& Coulson, T. 2009 The Dynamics of Phenotypic Change and the Shrinking Sheep of St. Kilda. Science 325, 464-467. (doi:10.1126/science.1173668). 
bioRxiv preprint doi: https://doi.org/10.1101/2021.01.06.425564; this version posted January 8,2021 . The copyright holder for this preprint (which was not certified by peer review) is the author/funder, who has granted bioRxiv a license to display the preprint in perpetuity. It is made available under aCC-BY-NC-ND 4.0 International license.

Genomic prediction and microevolution in Soay sheep

405

406

407

408

409

410

411

412

413

414

415

416

417

418

419

420

421

422

423

424

425

426

427

428

429

430

431

432

433

434

435

436

437

438

439

440

441

442

443

444

445

446

447

448

449

450

451

452

453

[20] Bérénos, C., Ellis, P.A., Pilkington, J.G. \& Pemberton, J.M. 2014 Estimating quantitative genetic parameters in wild populations: a comparison of pedigree and genomic approaches. Molec. Ecol. 23, 3434-3451. (doi:10.1111/mec.12827).

[21] Browning, S.R. \& Browning, B.L. 2007 Rapid and accurate haplotype phasing and missing-data inference for whole-genome association studies by use of localized haplotype clustering. American Journal of Human Genetics 81, 1084-1097. (doi:10.1086/521987).

[22] Meuwissen, T.H.E., Hayes, B.J. \& Goddard, M.E. 2001 Prediction of total genetic value using genome-wide dense marker maps. Genetics 157, 1819-1829.

[23] Clark, S.A., Hickey, J.M., Daetwyler, H.D. \& van der Werf, J.H. 2012 The importance of information on relatives for the prediction of genomic breeding values and the implications for the makeup of reference data sets in livestock breeding schemes. Genetics, selection, evolution : GSE 44, 4. (doi:10.1186/1297-9686-44-4).

[24] Clutton-Brock, T. \& Pemberton, J. 2004 Soay Sheep: dynamics and selection in an island population. (p. 383, Cambridge University Press.

[25] Bérénos, C., Ellis, P.A., Pilkington, J.G., Lee, S.H., Gratten, J. \& Pemberton, J.M. 2015

Heterogeneity of genetic architecture of body size traits in a free-living population. Molec. Ecol. 24, 1810-1830. (doi:10.1111/mec.13146).

[26] Kijas, J.W., Lenstra, J.A., Hayes, B., Boitard, S., Neto, L.R.P., San Cristobal, M., Servin, B., McCulloch, R., Whan, V., Gietzen, K., et al. 2012 Genome-Wide Analysis of the World's Sheep Breeds Reveals High Levels of Historic Mixture and Strong Recent Selection. PLoS Biology 10, e1001258. (doi:10.1371/journal.pbio.1001258).

[27] Johnston, S.E., Bérénos, C., Slate, J. \& Pemberton, J.M. 2016 Conserved Genetic Architecture Underlying Individual Recombination Rate Variation in a Wild Population of Soay Sheep (Ovis aries). Genetics 203, 583-598. (doi:10.1534/genetics.115.185553).

[28] Chang, C., Chow, C., Tellier, L., Vattikuti, S., Purcell, S. \& Lee, J. 2015 Second-generation PLINK: rising to the challenge of larger and richer datasets. GigaScience 4, 7. (doi:10.1186/s13742-0150047-8).

[29] Ashraf, B., Hunter, D.C., Bérénos, C., Ellis, P.A., Pilkington, J.G., Johnston, S.E., Pemberton, J.M. \& Slate, J. 2020 Genomic prediction in the wild: a case study in Soay sheep. bioRxiv. (doi:10.1101/2020.07.15.205385).

[30] Erbe, M., Hayes, B.J., Matukumalli, L.K., Goswami, S., Bowman, P.J., Reich, C.M., Mason, B.A. \& Goddard, M.E. 2012 Improving accuracy of genomic predictions within and between dairy cattle breeds with imputed high-density single nucleotide polymorphism panels. Journal of Dairy Science 95, 4114-4129. (doi:10.3168/jds.2011-5019).

[31] Moser, G., Lee, S.H., Hayes, B.J., Goddard, M.E., Wray, N.R. \& Visscher, P.M. 2015 Simultaneous Discovery, Estimation and Prediction Analysis of Complex Traits Using a Bayesian Mixture Model.

PLoS Genetics 11, e1004969. (doi:10.1371/journal.pgen.1004969).

[32] Bonnet, T., Wandeler, P., Camenisch, G. \& Postma, E. 2017 Bigger Is Fitter? Quantitative Genetic Decomposition of Selection Reveals an Adaptive Evolutionary Decline of Body Mass in a Wild Rodent Population. PLOS Biol 15, e1002592. (doi:10.1371/journal.pbio.1002592).

[33] Evans, S.R. \& Gustafsson, L. 2017 Climate change upends selection on ornamentation in a wild bird. Nat Ecol Evol 1, 39. (doi:10.1038/s41559-016-0039).

[34] Pigeon, G., Festa-Bianchet, M., Coltman, D.W. \& Pelletier, F. 2016 Intense selective hunting leads to artificial evolution in horn size. Evol App/ 9, 521-530. (doi:10.1111/eva.12358).

[35] Leal, S.M., Yan, K. \& Müller-Myhsok, B. 2005 SimPed: A Simulation Program to Generate Haplotype and Genotype Data for Pedigree Structures. Human Heredity 60, 119.

(doi:10.1159/000088914).

[36] Hendry, A.P., Farrugia, T.J. \& Kinnison, M.T. 2008 Human influences on rates of phenotypic change in wild animal populations. Mol Ecol 17, 20-29. (doi:10.1111/j.1365-294X.2007.03428.x). 
bioRxiv preprint doi: https://doi.org/101101/2021 01 06 425564; this version posted January 8, 2021. The copyright holder for this preprint (which was not certified by peer review) is the author/funder, who has granted bioRxiv a license to display the preprint in perpetuity. It is made available under aCC-BY-NC-ND 4.0 International license.

Genomic prediction and microevolution in Soay sheep

454 [37] Bonnet, T., Morrissey, M.B., Morris, A., Morris, S., Clutton-Brock, T.H., Pemberton, J.M. \& Kruuk, 455 L.E.B. 2019 The role of selection and evolution in changing parturition date in a red deer population.

456 PLOS Biol 17, e3000493. (doi:10.1371/journal.pbio.3000493).

457 